\title{
PENGARUH DUA SISTEM OLAH TANAH DAN APLIKASI HERBISIDA TERHADAP RESPIRASI TANAH PADA PERTANAMAN JAGUNG (Zea Mays L.) MUSIM TANAM KE-5
}

\section{THE EFFECT OF TWO SOILING SYSTEMS AND HERBICIDE APPLICATIONS ON SOIL RESPIRATION IN CORN (Zea Mays L.) PLANTING THE 5th SEASON}

\author{
Andri Tri Wicaksono ${ }^{1 *}$, A.Niswati ${ }^{2}$, M.A.S.Arif ${ }^{2}$ dan M.Utomo ${ }^{2}$ \\ ${ }^{1}$ Jurusan Agroteknologi ${ }^{2}$ Jurusan Ilmu Tanah Fakultas Pertanian Universitas Lampung, \\ Bandarlampung, Indonesia \\ Email: andritiga3@gmail.com
}

*Corresponding Author, Diterima: 6 Sept. 2021 , Direvisi: 20 Okt. 2021 , Disetujui: 25 Des. 2021

\begin{abstract}
Corn is one of the important crops in Lampung. The amount of demand for corn is not accordance with the current availability of corn this period because of the low amount of production. Poor cultivation systems make low production which is influenced by the soil cultivation process, until the result of soil is damage. One way to maintain soil productivity is by modifying the method of soil and the intensity of cultivation of soil. This research aims to study the effect of two cultivation soil systems on maize (Zea mays L.), the effect of herbicide applications on soil respiration in maize (Zea mays L.) and the effect of the interaction between cultivation soil systems and herbicide applications toward the soil respiration in the crop of maize (Zea mays L.) 5th crop. The research was conducted at the Integrated Lap Lab, University of Lampung. The design used in the research was a factorial randomized block design with two factors consisting of the cultivation soil systems and herbicide applications. The data were analyzed using variance at the $5 \%$ level, which was tested for homogeneity of the variance first with the Bartlett test and the addivity was tested by the Tukey test. The Average of mean of the data was tested by the BNT test at the 5\% level. The relationship between $\mathrm{pH}$, soil temperature, $\mathrm{C}$-organic, water content and soil respiration was known by the correlation test. The research results showed that the treatment of the cultivation soil system had no real significant effect toward the soil respiration in all phases of observation. Herbicide application treatment significantly affected soil respiration in the generative phase observations, but was not the observations before cultivation soil, after the cultivation soil and the vegetative phase. There was no interaction between the two cultivation soil systems and herbicide application toward soil respiration in all phases of observation.
\end{abstract}

Keywords: Application of herbicides, corn, minimum cultivation, soil respiration.

\begin{abstract}
ABSTRAK
Tanaman jagung merupakan salah satu tanaman penting di Lampung. Banyaknya permintaan jagung tidak sesuai dengan ketersediaanjagung saat ini karena jumlah produksi yang rendah. Sistem budidaya yang buruk membuat produksinya rendah yang dipengaruhi oleh proses pengolahan tanah sehingga terjadi kerusakan tanah. Salah satu cara mempertahankan produktivitas tanah yaitu dengan memodifikasi cara olah tanah dan intensitas pengolahan tanah. Penelitian ini bertujuan untuk Mempelajari pengaruh dua sistem pengolahan tanah pada pertanaman jagung (Zea mays L.), pengaruh aplikasi herbisida terhadap respirasi tanah pada pertanaman jagung (Zea mays L.) dan pengaruh interaksi antara sistem olah tanah dan aplikasi herbisida terhadap respirasi tanah pada pertanaman jagung (Zea mays L.) pertanaman ke-5. Penelitian dilakukan di Lab Lap Terpadu Universitas Lampung. Rancangan yang digunakan pada penelitian adalah Rancangan Acak Kelompok faktorial dengan dua faktor yang terdiri dari sistem olah tanah dan aplikasi herbisida. Data dianalisis dengan sidik ragam pada taraf $5 \%$ yang diuji homogenitas ragamnya dahulu dengan Uji Bartlett dan adivitasnya diuji dengan Uji Tukey. Rata-rata nilai tengah dari data diuji dengan uji BNT pada taraf 5\%. Hubungan antara $\mathrm{pH}$, suhutanah, C-organik, kadar air dengan respirasi tanah diketahui dengan uji korelasi. Hasil penelitian menunjukkan Perlakuan sistem olah tanah tidak berpengaruh nyata terhadap respirasi tanah pada semua fase
\end{abstract}


pengamatan. Perlakuan aplikasi herbisida berpengaruh nyata terhadap respirasi tanah pada pengamatan fase generatif, tetapi tidak pada pengamatan sebelum olah tanah, setelah olah tanah dan fase vegetatif. Tidak terdapat interaksi antara dua sistem olah tanah dan aplikasi herbisida terhadap respirasi tanah pada semua fase pengamatan.

Kata kunci: Aplikasi herbisida, jagung, olah tanah minimum, respirasi tanah.

\section{PENDAHULUAN}

Tanaman jagung (Zea mays L.) merupakan salah satu tanaman pangan penting di Provinsi Lampung. Jagung mempunyai peranan yang penting dan bernilai ekonomis sehingga mempunyai peluang untuk dikembangkan, karena komoditas ini mempunyai banyak fungsi, selain untuk pangan juga dapat digunakan sebagai pakan ternak dan industri. Banyaknya permintaan jagung tidak sesuai dengan ketersediaan jagung saat ini, karena jumlah produksi yang rendah.

Sistem budidaya pertanian tidak lepas dari proses pengolahan tanah. Tanah merupakan media tumbuhnya tanaman, dimana perannya sangat penting bagi pertumbuhan tanaman (Yuliprianto, 2010). Tanah menjadi salah satu sumber daya alam yang penting dan perlu mendapat perhatian sungguh-sungguh agar terhindar dari kerusakan yang dapat menurunkan produktivitas tanah.

Kerusakan tanah dapat terjadi karena salah dalam pengolahannya. Banyak usaha yang dapat dilakukan untuk mempertahankan produktivitas tanah, diantaranya adalah melalui modifikasi cara olah tanah dan intensitas pengolahan tanah. Pengolahan tanah merupakan kegiatan manipulasi mekanik terhadap tanah agar mampu menciptakan keadaan tanah yang baik bagi pertumbuhan tanaman. Pengolahan tanah bertujuan untuk menyediakan tempat tumbuh bagi bibit tanaman, memperbaiki daerah perakaran, membenamkan sisa-sisa tanaman, dan mengendalikan gulma (Habiby dkk., 2013).

Pengolahan tanah yang baik akan memperbaiki sifat fisik tanah, sifat biologi tanah maupun menciptakan kondisi yang sesuai untuk pertumbuhan tanaman. Salah satu cara memperbaiki sifat fisik dan biologi tanah yaitu dengan cara pengolahan tanah. Menurut Suripin (2010), pengolahan tanah mampu memperbaiki daerah perakaran tanaman, kelembaban dan aerasi tanah, mempercepat infiltrasi serta mengendalikan tumbuhan pengganggu. Pengolahan yang biasa dilakukan adalah olah tanah maksimum (intensif) dan olah tanah minimum (konservasi).Kedua metode tersebut mempunyai kelemahan dan keunggulan masing- masing baik untuk jangka pendek ataupun jangka panjang. Sistem olah tanah yang sering digunakan oleh petani adalah sistem olah tanah maksimum karena lebih efisien waktu dan tenaga, dimana sistem olah tanah ini mewajibkan tindakan pembongkaran dan penggemburan tanah sampai kedalaman tertentu. Namun dengan pengolahan tanah yang dilakukan secara terus menerus dapat menimbulkan dampak negatif bagi produktivitas lahan.

Menurut Utomo, dkk. (2012), pengolahan tanah yang dilakukan terus menerus dapat menimbulkan dampak negatif terhadap sifat fisik dan biologi tanah yaitu mampu memnyebabkan terjadinya degradasi tanah, kerusakan struktur tanah, peningkatan terjadinya erosi tanah, pemadatan tanah, dan penurunan kadar bahan organik tanah yang mampu mempengaruhi keberadaan biota bawah tanah. Selain itu, pengolahan tanah intensif juga dapat menyebabkan kehilangan karbon di dalam tanah yang dapat menurunkan cadangan karbon yang tersimpan di dalam tanah. Akibat yang ditimbulkan oleh penggunaan sistem olah tanah maksimum seperti tingginya erosi dan pemadatan tanah di lahan pertanian yang dapat menurunkan produktivitas tanah dan menyebabkan air tanah terbuang melalui penguapan atau drainase.

Olah tanah minimum merupakan kegiatan olah tanah konservasi yang bertujuan untuk menyiapkan lahan agar tanaman dapat tumbuh dan berproduksi optimum dengan tetap memperhatikan konservasi tanah dan air (Utomo, 2012). Olah tanah minimum memanfaatkan gulma dan sisa tanaman sebagai mulsa penutup tanah untuk menambah bahan organik tanah. Penggunaan gulma dan sisa tanaman sebagai mulsa mempunyai peran positif bagi lahan dan mikroorganisme tanah.

Aplikasi herbisida yang merupakan bagian tak terpisahkan yang dilakukan pada kegiatan penyiapan lahan, karena dengan aplikasi herbisida tidak memerlukan banyak tenaga kerja, lebih efisien waktu dan biaya. Penggunaan herbisida dengan tepat waktu dan tepat dosis tidak mempengaruhi mikroorganisme yang ada.

Herbisida mempunyai peran positif dalam mematikan gulma maupun sisa tanaman yang 
masih hidup, yang selanjutnya gulma dan sisa tanaman dapat dimanfaatkan sebagai mulsa dan bahan organik. Menurut Burhanuddin dkk., (2015), penggunaan herbisida terbukti mampu mengurangi secara nyata kehilangan top soil sekaligus menciptakan iklim mikro yang kondusif bagi pertumbuhan tanaman dan mampu meningkatkan kesuburan tanah.

Respirasi tanah merupakan indikator penting pada suatu ekosistem, meliputi seluruh aktivitas yang berkenaan dengan proses metabolisme di dalam tanah dan dekomposisi sisa tanaman dalam tanah. Respirasi tanah menggambarkan aktivitas mikroorganisme tanah. Respirasi tanah adalah proses hilangnya $\mathrm{CO}_{2}$ dari tanah ke atmosfer, terutama yang dihasilkan oleh mikroorganisme tanah dan akar tanaman. Menurut Utomo, dkk. (2012), respirasi tanah adalah proses ekosistem yang berkaitan erat dengan produktivitas ekosistem, kesuburan tanah, siklus karbon, perubahan iklim, perdagangan karbon dan kebijakan lingkungan. Pengukuran respirasi (mikroorganisme) tanah merupakan cara yang pertama kali digunakan untuk menentukan tingkat aktivitas mikroorganisme tanah. Haney, dkk. (2008) mengatakan bahwa respirasi tanah merupakan aspek penting dari kualitas tanah dan indicator kesuburan tanah. Tujuan dari dilakukannya penelitian ini adalah Mempelajari pengaruh dua sistem pengolahan tanah pada pertanaman jagung (Zea mays L.) pertanaman ke5, Mempelajari pengaruh aplikasi herbisida terhadap respirasi tanah pada pertanaman jagung (Zea mays L.) pertanaman ke-5 dan Mempelajari pengaruh interaksi antara sistem olah tanah dan aplikasi herbisida terhadap respirasi tanah pada pertanaman jagung (Zea mays L) pertanaman ke-5.

\section{BAHAN DAN METODE}

Penelitian ini dilaksanakan pada bulan 15 Oktober 2016 -29 Januari 2017 pada lahan percobaan di Laboratorium Lapang Terpadu, Fakultas Pertanian, Universitas Lampung.Analisis vegetasi dan sampel tanah dilakukan di Laboratorium Ilmu Tanah dan Laboratorium Biologi Tanah Lantai 2, Fakultas Pertanian, Universitas Lampung.

Alat yang digunakan dalam penelitian ini yaitu toples, plastik, kertas label, botol film, sabit, cangkul, buret, gelas ukur, tabung ukur, erlenmeyer, pipet tetes, botol kimia, $\mathrm{pH}$ meter, termometer tanah dan alat titrasi. Sedangkan bahan yang digunakan dalam penelitian ini yaitu sampel tanah, $\mathrm{KOH} 0,1 \mathrm{~N}$, penolptalin, aquades, $\mathrm{HCl}$, metil orange, pupuk kimia (Urea, TSP dan KCL), pupuk organonitrofos, pupuk kimia (Urea, TSP dan KCL), benih jagung hibrida dan herbisida berbahan aktif isopopilamina glifosat $+2,4 \mathrm{D}$.

Penelitian ini dirancang dengan menggunakan Rancangan Acak Kelompok (RAK) secara faktorial yang terdiri dari dua faktor yaitu sistem olah tanah dan aplikasi herbisida. Sistem olah tanah terdiri dari olah tanah minimum $\left(\mathrm{T}_{1}\right)$ dan olah tanah maksimum $\left(\mathrm{T}_{2}\right)$. Sedangkan aplikasi herbisida terdiri dari aplikasi herbisida $\left(\mathrm{H}_{1}\right)$ dan non aplikasi herbisida $\left(\mathrm{H}_{0}\right)$. Demikian terbentuk empat kombinasi perlakuan yaitu: $\mathrm{T}_{1} \mathrm{H}_{1}=$ olah tanah minimum + aplikasi herbisida, $\mathrm{T}_{1} \mathrm{H}_{0}=$ olah tanah minimum + non aplikasi herbisida, $\mathrm{T}_{2} \mathrm{H}_{1}=$ olah tanah maksimum + aplikasi herbisida dan $\mathrm{T}_{2} \mathrm{H}_{0}=$ olah tanah maksimum + non aplikasi herbisida.

Setiap perlakuan diulang sebanyak empat kali, sehingga diperoleh 16 petak percobaan. Data yang diperoleh dianalisis dengan sidik ragam pada taraf $5 \%$ yang terlebih dahulu diuji homogenitas ragamnya dengan menggunakan Uji Bartlett dan adivitasnya diuji dengan Uji Tukey. Rata-rata nilai tengah dari data diuji dengan uji BNT pada taraf $5 \%$. Hubungan antara $\mathrm{pH}$, suhu tanah, C-organik, kadar air dengan respirasi tanah diketahui dengan uji korelasi.

\subsection{Pelaksanaan Penelitian Penyiapan Lahan}

Persiapan lahan untuk petakan yang diterapkan sistem olah tanah minimum (OTM) dan olah tanah intensif (OTI) masing-masing terdiri dari dua perlakuan, yaitu sistem OTM dengan aplikasi herbisida, sistem OTM tanpa aplikasi herbisida, sistem OTI dengan aplikasi herbisida dan sistem OTI tanpa aplikasi herbisida. Persiapan lahan OTM dan OTI dengan aplikasi herbisida diawali dengan penyemprotan herbisida berbahan aktif isopropilamina glisofat $+2,4 \mathrm{D}$ dengan dosis $160 \mathrm{ml} /$ 1 tangki ( 1 tangki= 16 liter $)$.

Penyemprotan herbisida dilakukan pada saat persiapan lahan dan 23 hari setelah tanam (HST). Pada lahan OTM, gulma yang telah mati dan serasah sisa tanaman ubi kayu sebelumnya dibiarkan dilahan sebagai mulsa. Tetapi pada lahan OTI dengan aplikasi herbisida setelah dilakukan penyemprotan herbisida, kemudian lahan dicangkul sebanyak 2 kali hingga bongkahan tanah menjadi gembur serta gulma dan sisa-sisa tanaman pengganggu lainnya dibersihkan dari lahan.

Penanaman benih jagung dilakukan pada 
tanggal 15 Oktober 2016. Benih jagung ditanam sebelumnya diberi perlakuan dengan insektisida dan zat pengatur tumbuh berbahan aktif fipronil, setiap lubang tanam berisi 2 benih dengan jarak tanam 70 $\mathrm{cm}$ x $30 \mathrm{~cm}$. Seminggu setelah tanam dilakukan pemupukan dengan pupuk organik organonitrofos sebanyak 20 tonha $^{-1}$ atau $24 \mathrm{~kg} \mathrm{plot}^{-1}$, pemupukan dilakukan dengan cara dilarik.

Setelah seminggu kemudian dilakukan pemupukan kembali dengan pupuk kimia, yaitu 400 kg.ha ${ }^{-1}$ urea, 300 kgha $^{-1}$ TSP dan 400 kg.ha ${ }^{-1} \mathrm{KCl}$. Masing-masing petakan lahan diberi pupuk tersebut dengan dosis 240gram urea, 480gram TSP dan 480 gram KCl. Pemupukan urea diberikan dalam dua tahap yaitu pada awal tanam dengan $2 / 3$ dosis dan pada saat pertumbuhan vegetatif $1 / 3$ dosis. Sebelum dilakukan pemupukan pada lahan dengan OTI dilakukan pengguludan, sedangkan pada lahan dengan OTM dilakukan pemotongan gulma dan bekas pemotongan di biarkan di antara tanaman.

Petak percobaan dibuat sesuai dengan perlakuan yang diterapkan, yaitu: dibuat secara berkelompok yaitu empat perlakuan pengolahan tanah dan aplikasi herbisida dan diulang sebanyak 4 kali dengan perlakuan yang diterapkan.

\subsection{Pengukuran Respirasi Tanah}

Respirasi tanah diukur menggunakan metode Verstraete yang dimodifikasi yaitu pengukuran $\mathrm{CO}_{2}$ dari tanah ke atmosfer dengan menggunakan metode ruang tertutup (Anas, 1989). Hendri (2014) juga menggunakan metode ruang tertutup untuk pengukuran fluks $\mathrm{CO}_{2}$ dan $\mathrm{N}_{2} \mathrm{O}$ dari tanah. Respirasi tanah menggambarkan aktivitas mikroorganisme tanah, metode respirasi tanah masih sering digunakan karena cukup peka, konsisten, sederhana,dan tidak memerlukan alat yang canggih dan mahal.Pengambilan sampel dilakukan pagi dan sore hari. Pengambilan sampel respirasi tanah dilakukan diantara baris tanaman jagung.

Pengambilan sampel ini dilakukan pada waktu sebelum olah tanah, setelah olah tanah, fase vegetatif dan fase generatif. Langkah dalam pengambilan sampel untuk pengukuran $\mathrm{CO}_{2}$ atau respirasi tanah yaitu botol film yang diisi $10 \mathrm{ml} 0,1$ $N \mathrm{KOH}$, diletakkan di atas tanah dengan keadaan terbuka di petak percobaan lalu ditutup dengan sungkup dan sungkup tersebut dimasukkan ke dalam tanah sekitar $1 \mathrm{~cm}$ lalu pinggirnya dibunbun dengan tanah agar tidak ada gas yang keluar dari sungkup. Hal yang sama dilakukan untuk blangko $\mathrm{KOH}$ diletakkan di atas tanah yang telah dialasi dengan plastik di sebelah $\mathrm{KOH}$ tanpa alas plastik.Setelah sungkup diletakkan, dibiarkan selama 2 jam. Setelah 2 jam, sungkupnya dibuka dan botol yang berisi $\mathrm{KOH}$ langsung ditutup agar tidak terjadi kontaminan dari gas $\mathrm{CO}_{2}$ dari lingkungan sekitarnya.

\subsection{Analisis Laboraturium}

Analisis dilaboratorium menggunakan metode Verstraete (Anas, 1989), sampel $\mathrm{KOH}$ yang telahmengikat $\mathrm{CO}_{2}$ dari lapangan kemudian dianalisis di laboratorium dengan cara dititrasi. Botol film (sampel) yang berisi KOH dimasukkan ke dalam erlenmeyer, lalu ditetesi dengan 2 tetes penolptalin, dan kemudian dititrasi dengan $0,1 \mathrm{~N}$ HClhingga warna merah muda atau merah hilang. Volume $\mathrm{HCl}$ yang digunakan untuk titrasi tersebut dicatat. Selanjutnya pada larutan tersebut ditambah 2 tetes metyl orangedan terjadi perubahan warna menjadi kuning atau orange, kemudian dititrasi kembali dengan $\mathrm{HCl}$ hingga warna kuning atau orange berubah menjadi warna merah muda. Jumlah $\mathrm{HCl}$ yang digunakan pada tahap kedua ini berhubungan langsung dengan jumlah $\mathrm{CO}_{2}$ yang difiksasi. Demikian juga dengan $\mathrm{KOH}$ dari sampel blanko dilakukanprosedur yang sama dengan $\mathrm{KOH}$ sampel.Pengamatan respirasi dilakukan pada pagi dan sore hari.

Reaksi kimia yang terjadi selama proses titrasi $\mathrm{CO}_{2}$ dan dilanjutkan dengan titrasi menggunakan $\mathrm{HCl}$ adalah sebagai berikut :

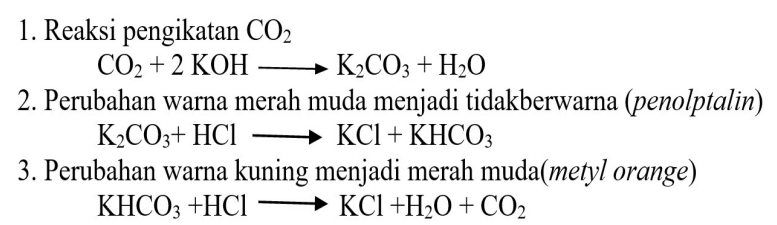

\subsection{Perhitungan Respirasi Tanah}

Respirasi tanah dapat dihitung dengan menggunakan rumus sebagai berikut :

$$
\mathrm{C}-\mathrm{CO}=\frac{(\mathrm{a}-\mathrm{b}) \times \mathrm{t} \times 12}{\mathrm{~T} \times \pi \times \mathrm{r}^{2}}
$$

Keterangan : $\mathrm{C}_{-} \mathrm{CO}_{2}=\mathrm{mg} \mathrm{jam}^{-1} \mathrm{~m}^{-2}, \mathrm{a}=\mathrm{ml} \mathrm{HCl}$ untuk sampel $b=\mathrm{ml} \mathrm{HCl} \mathrm{untuk} \mathrm{blanko} \mathrm{t}=$ normalitas $(N) \mathrm{HCl}, \mathrm{T}=$ waktu $($ jam) dan $\mathrm{r}=$ jari-jari tabung toples $(\mathrm{cm})$.

\subsection{Variabel Pendukung}

Variabel pengamatan pada penelitian ini diamati pada saat sebelum dan setelah perlakuan kemudian 
pada fase vegetatif dan fase generatif yaitu meliputi suhu Tanah $\left({ }^{\circ} \mathrm{C}\right)$ (diukur dengan Soil Thermometer Tester), Kadar air(metode gravimetri), C-organik tanah(metode Walkley and Black) dan $\mathrm{pH}$ Tanah (metode elektrometrik).

Sampel tanah variable pendukung diambil pada waktu yang sama dengan pengambilan sampel untuk respirasi yaitu, sebelum olah tanah, setelah olah tanah, fase vegetative dan fase generative. Sampel tanah variable pendukung diambil dengan menggunakan bor tanah dari 5 titik pada masingmasing plot percobaan dan kemudian dikompositkan. Tata letak pengambilan sampel tanah digambarkan pada gambar 1 .

\section{HASIL DAN PEMBAHASAN}

\subsection{Pengaruh Sistem Olah Tanah dan Aplikasi Herbisida terhadap Respirasi Tanah}

Ringkasan hasil analisis ragam respirasi tanah pada pengamatan sebelum olah tanah, setelah olah tanah, fase vegetatif tanaman dan fase generatif tanaman (Tabel 1) menunjukkan bahwa perlakuan pengolahan tanah tidak berpengaruh nyata terhadap respirasi tanah pada semua fase pengamatan. Sedangkan pada perlakuan aplikasi herbisida menunjukkan pengaruh nyata terhadap respirasi tanah pada fase generatif. Interaksi antara

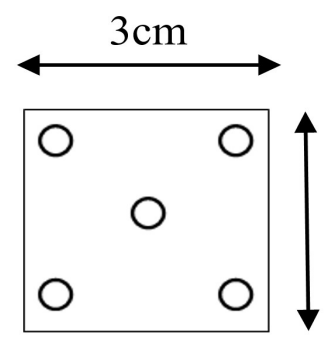

Gambar 1. Tata Letak Pengambilan Sampel Tanah Tiap Petak Percobaan Variabel Pendukung.

O : Letak Pengambilan Sampel Tanah. perlakuan pengolahan tanah dan aplikasi herbisida pada semua pengamatan tidak berpangaruh nyata terhadap respirasi tanah. Hasil uji lanjut BNT 5\% (Tabel 2) menunjukan bahwa respirasi tanah berbeda nyata dan lebih tinggi dibandingkan dengan tanpa aplikasi herbisida pada pengamatan pada fase generatif.

\subsection{Pengaruh Pengolahan Tanah dan Aplikasi Herbisida terhadap Kadar Air Tanah, Suhu Tanah, C-organik dan pH tanah.}

Pengaruh pengolahan tanah dan aplikasi herbisida terhadap kadar air tanah. (Tabel 3) menunjukkan bahwa pada setelah olah tanah, pada fase vegetatif dan generatif perlakuan pengolahan tanah, herbisida dan interaksi antara herbisida dan pengolahan tanah tidak berpengaruh nyata terhadap kadar air tanah. Sedangkan pada sebelum pengolahan tanah herbisida berpengaruh nyata terhadap kadar air tanah. Berdasarkan uji BNT 5\% (Tabel 4), menunjukan kadar air tanah berbeda nyata dan lebih tinggi dibandingkan dengan perlakuan aplikasi herbisida.

Pengaruh pengolahan tanah dan aplikasi herbisida terhadap suhu tanah. Hasil analisis ragam (Tabel 5) menunjukkan pada sebelum olah tanah, setelah olah tanah, dan fase vegetatif tanaman dan fase genertaif tanaman pada perlakuan pengolahan tanah dan perlakuan herbisida dan interaksi antara herbisida dan pengolahan tanah tidak berpengaruh nyata terhadap suhu tanah. Artinya suhu tanah tidak berpengaruh nyata pada semua fase pengamatan.

Pengaruh pengolahan tanah dan aplikasi herbisida terhadap C-organik tanah (\%). Hasil analisis ragam (Tabel 6) menunjukkan pada sebelum olah tanah, setelah olah tanah, fase vegetative dan fase generatif tanaman pada perlakuan pengolahan tanah, herbisida dan interaksi antara herbisida dan pengolahan tanah tidak berpengaruh nyata terhadap C-organik tanah (\%).

Tabel 1. Ringkasan Signifikasi Pengaruh Pengolahan Tanah dan Aplikasi Herbisida terhadap Respirasi Tanah $\mathrm{CO}_{2}-\mathrm{C}$ pada Fase Pengolahan Tanah dan Fase Pertumbuhan Tanaman.

\begin{tabular}{ccccc}
\hline \multirow{2}{*}{ Perlakuan } & \multicolumn{4}{c}{ F. hitung dan signifikan } \\
\cline { 2 - 5 } & Sebelum OT & Setelah OT & Fase VT & Fase GT \\
\hline Olah Tanah (T) & $0,01^{\text {tn }}$ & $4,76^{\text {th }}$ & $0,15^{\text {th }}$ & $0,03^{\text {th }}$ \\
AplikasiHerbisida (H) & $0,27^{\text {tn }}$ & $0,76^{\text {th }}$ & $4,70^{\text {tn }}$ & $10,38^{*}$ \\
T x H & $4,76^{\text {th }}$ & $0,08^{\text {th }}$ & $1,32^{\text {tn }}$ & $4,86^{\text {th }}$ \\
\hline
\end{tabular}

Keterangan : tn $=$ Tidak berpengaruh nyata pada taraf $5 \% ; *=$ Berbeda nyata pada taraf $5 \%$; OT $=$ Olah Tanah ; $\mathrm{VT}=$ Vegetatif tanaman $; \mathrm{GT}=$ Generatif tanaman 
Tabel 2. Uji BNT Perlakuan Aplikasi Herbisida terhadap Respirasi Tanah pada Fase Generatif Tanaman.

\begin{tabular}{cc}
\hline Perlakuan & Respirasi $\left(\mathrm{CO}_{2}-\mathrm{C}\left(\mathrm{mg} \mathrm{jam}^{-1} \mathrm{~m}^{-2}\right)\right.$ \\
\hline $\mathrm{H}_{1}$ & $12,1 \mathrm{a}$ \\
$\mathrm{H}_{2}$ & $15,8 \mathrm{~b}$ \\
\hline BNT 5\% & 3,3 \\
\hline
\end{tabular}

Keterangan : Angka yang diikuti oleh huruf yang sama tidak berbeda nyata dengan uji BNT pada taraf 5\%.

Tabel 3. Ringkasan Signifikasi Pengaruh Pengolahan Tanah dan Aplikasi Herbisida terhadap Kadar Air Tanah (\%) pada Pengolahan Tanah dan Fase Pertumbuhan Tanaman.

\begin{tabular}{ccccc}
\hline \multirow{2}{*}{ Perlakuan } & \multicolumn{4}{c}{ F. hitung dan signifikan } \\
\cline { 2 - 5 } & Sebelum OT & Setelah OT & Fase VT & Fase GT \\
\hline Olah Tanah (T) & $0,01^{\text {tn }}$ & $0,01^{\text {tn }}$ & $0,02^{\text {tn }}$ & $1,92^{\text {tn }}$ \\
AplikasiHerbisida (H) & $10,13^{*}$ & $0,03^{\text {tn }}$ & $0,05^{\text {tn }}$ & $0,26^{\text {tn }}$ \\
T x H & $0,92^{\text {tn }}$ & $0,02^{\text {tn }}$ & $0,20^{\text {tn }}$ & $0,52^{\text {n }}$ \\
\hline
\end{tabular}

Keterangan : $\mathrm{tn}=$ Tidak berpengaruh nyata pada taraf $5 \% ; *=$ Berbeda nyata pada taraf 5\%; OT $=$ Olah Tanah ; $\mathrm{VT}=$ Vegetatif tanaman $; \mathrm{GT}=$ Generatif tanaman .

Pengaruh pengolahan tanah dan aplikasi herbisida terhadap $\mathrm{pH}$ tanah. Hasil analisis ragam (Tabel 7) menunjukkan pada sebelum olah tanah, setelah olah tanah, fase vegetatif dan fase generatif tanaman pada perlakuan pengolahan tanah dan perlakuan herbisida dan interaksi antara herbisida dan pengolahan tanah tidak berpengaruh nyata terhadap pH tanah. Menurut Lay (1994), bakteri dan mikroorganisme dapat tumbuh dengan baik pada pH sekitar 7 (netral) meskipun dapat tumbuh kisaran $\mathrm{pH}$ 5-8. Semakin netral $\mathrm{pH}$ maka mikroorganisme akan tumbuh dengan baik dan semakin tinggi aktivitas mikroorganisme. Nilai $\mathrm{pH}$ pada semua fase pengamatan dikatakan agak asam atau mendekati netral dimana bakteri dan mikroorganisme masih dapat tumbuh dengan baik. Nilai $\mathrm{pH}$ dari masing-masing fase pengamatan juga tidak terlalu berbeda, sehingga pengaruh pengolahan tanah dan perlakuan aplikasi herbisida terhadap $\mathrm{pH}$ tanah pada semua fase pengamatan menunjukkan tidak berpengaruh nyata.

\subsection{Korelasi antara Suhu Tanah, Kadar Air tanah, pH Tanah, dan C-organik Tanah dengan Respirasi Tanah.}

Hasil uji korelasi (Tabe18) menunjukkan tidak terdapat korelasi antara suhu tanah, kadar air tanah, $\mathrm{pH}$ tanah, dan C-organik tanah dengan respirasi tanah.

\subsection{Pembahasan}

Hasil analisis ragam pengaruh pengolahan tanah dan aplikasi herbisida terhadap respirasi tanah pada fase sebelum olah tanah, setelah olah tanah, fase vegetative tanaman dan fase generatif tanaman (Tabel 1) menunjukkan bahwa perlakuan pengolahan tanah tidak berpengaruh nyata terhadap respirasi tanah pada semua pengamatan. Hal ini sejalan dengan penelitian Fahmi (2016) yang telah melakukan penelitian yang sama dengan tanaman berbeda pada juni 2014 hingga tahun 2015 dimana dari hasil penelitian menunjukkan belum adanya pengaruh sistem olah tanah dan aplikasi herbisida terhadap respirasi tanah. Perlakuan sistem olah tanah dalam kurun waktu yang singkat juga diduga belum mampu memperlihatkan pengaruh nyata terhadap peningkatan kandungan bahan organik tanah.

Perlakuan aplikasi herbisida pada pengamatan sebelum olah tanah, setelah olah tanah dan fase vegetatif tidak berpengaruh nyata, sedangkan perlakuan aplikasi herbisida berpengaruh nyata terhadap respirasi tanah pada fase generatif tanaman. Perlakuan aplikasi herbisida menunjukkan pengaruh nyata terhadap respirasi tanah pada fase generatif tanaman (Tabel 2), hal ini diduga karena pengaplikasian herbisida berbahan aktif isopropil amina $+2,4 \mathrm{D}$ yang mampu mengendalikan, menghambat dan mematikan gulma yang memiliki perakaran dalam yang kemudian terakumulasi dan akan mengalami proses dekomposisi serta mampu meningkatkan bahan organik tanah. Proses dekomposisi memerlukan waktu yang cukup lama hingga menjadi bahan organik.

Bahan organik berperan dalam menyediakan makanan dan tempat hidup untuk organisme tanah dan menyediakan energi untuk proses-proses biologi 
Tabel 4. Pengaruh Aplikasi Herbisida terhadap Kadar Air Tanah (\%) pada Saat Sebelum Olah Tanah.

\begin{tabular}{cc}
\hline Aplikasi Herbisida & Kadar air (\%) \\
\hline $\mathrm{H}_{0}$ & $24,4 \mathrm{~b}$ \\
$\mathrm{H}_{1}$ & $22,2 \mathrm{a}$ \\
\hline BNT 5\% & 2,0 \\
\hline
\end{tabular}

Keterangan : Angka yang diikuti oleh huruf yang sama tidak berbeda nyata dengan uji BNT pada taraf 5\%.

Tabel 5. Ringkasan Signifikasi Pengaruh Pengolahan Tanah dan Aplikasi Herbisida terhadap Suhu Tanah $\left({ }^{\circ} \mathrm{C}\right)$ pada Fase Pengolahan Tanah dan Fase Pertumbuhan Tanaman.

\begin{tabular}{ccccc}
\hline \multirow{2}{*}{ Perlakuan } & \multicolumn{3}{c}{ F. hitung dan signifikan } \\
\cline { 2 - 5 } & Sebelum OT & Setelah OT & Fase VT & Fase GT \\
\hline Pengolahan Tanah (T) & $3,35^{\text {tn }}$ & $0,06^{\text {tn }}$ & $3,85^{\text {tn }}$ & $0,71^{\text {tn }}$ \\
AplikasiHerbisida (H) & $0,35^{\text {tn }}$ & $0,33^{\text {tn }}$ & $0,15^{\text {tn }}$ & $2,54^{\text {n }}$ \\
T x H & $0,81^{\text {tn }}$ & $0,06^{\text {tn }}$ & $0,02^{\text {tn }}$ & $0,01^{\text {tn }}$ \\
\hline
\end{tabular}

Keterangan : $\mathrm{tn}=$ Tidak berpengaruh nyata pada taraf $5 \% ; *=$ Berbeda nyata pada taraf $5 \%$; OT $=$ Olah Tanah ; $\mathrm{VT}=$ Vegetatif tanaman $; \mathrm{GT}=$ Generatif tanaman.

Tabel 6. Ringkasan Signifiksi Pengaruh Pengolahan Tanah dan Aplikasi Herbisida terhadap C-Organik Tanah (\%) pada Sebelum Olah Tanah dan Fase Generatif Tanaman.

\begin{tabular}{ccc}
\hline \multirow{2}{*}{ Perlakuan } & \multicolumn{2}{c}{ F. hitung dan signifikan } \\
\cline { 2 - 3 } & Sebelum OT & Fase GT \\
\hline Pengolahan Tanah (T) & $2,06^{\text {th }}$ & $3,52^{\text {tn }}$ \\
AplikasiHerbisida (H) & $0,48^{\text {tn }}$ & $0,57^{\text {th }}$ \\
T x H & $0,24^{\text {th }}$ & $0,13^{\text {th }}$
\end{tabular}

Keterangan : tn $=$ Tidak berpengaruh nyata pada taraf $5 \% ; *=$ Berbeda nyata pada taraf $5 \%$; OT $=$ Olah Tanah ; $\mathrm{VT}=$ Vegetatif tanaman $; \mathrm{GT}=$ Generatif tanaman .

tanah termasuk respirasi tanah. Menurut Widdiana (1995), bahan organik mampu meningkatkan aktivitas dan mempengaruhi jumlah dan jenis mikroorganisme tanah. Pengaruh akar-akar tanaman pada fase generative diduga juga mampu memberikan sumbangan terhadap peningkatan karbon di dalam tanah. Interaksi antara perlakuan system olah tanah dan aplikasi herbisida pada semua pengamatan tidak berpengaruh nyata terhadap respirasi tanah (Tabel 2). Perlakuan system olah tanah dikatakan memiliki pengaruh yang sama pada setiap taraf dari perlakuan aplikasi herbisida, maka kedua factor tersebut saling bebas dan dikatakan tidak ada interaksi.

Pengaruh pengolahan tanah da perlakuan aplikasi herbisida terhadap suhu, C-organik dan $\mathrm{pH}$ tanah (Tabel 5) menunjukkan pada setelah olah tanah, fase vegetatif tanaman dan fase generatif tanaman pada 2 sistem pengolahan tanah, perlakuan aplikasi herbisida dan interaksi antara dua sistem pengolahan tanah da naplikasi herbisida tidak berpengaruh nyata. Sedangkan, kadar air tanah berpengaruh nyata pada perlakuan herbisida dipengamatan sebelum olah tanah. Hal ini diduga karena pada penelitian sebelumnya sisa hasil panen diletakka nkembali di atas permukaan tanah yang kemudian terdekomposisi menjadi bahan organik.

Tingginya bahan organik juga mampu memperbaiki struktur tanah dan berperan dalam pembentukan tanah dan juga meningkagkan daya simpan lengas tanah karena bahan organik mempunyai daya lengas yang tinggi, (Rajiman, dkk, 2008). Tingginya curah hujan juga diduga menjadi peran yang mempengaruhi tingginya kadar air tanah. Semakin tinggi curah hujan maka akan semakin baik pertumbuhan bagi gulma dan vegetasi lain di permukaan tanah. Menurut Hanafia (2004), terdapat faktor-faktor yang mempengaruhi kadar air tanah adalah tekstur tanah, kadar bahan organik, senyawa kimia dan kedalaman solum atau lapisan tanah.

Banyaknya vegetasi yang tumbuh di atas permukaan tanah seperti gulma dan tanaman lain pada pengamatan sebelum olah tanah juga didug a menjadi salah satu faktor tingginya kelembaban dan kadar air pada pengamatan sebelum olah tanah. 
Tabel 7. Ringkasan Signifikasi Pengaruh Pengolahan Tanah dan Aplikasi Herbisida terhadap pH Tanah pada Fase Pengolahan Tanah dan Fase Pertumbuhan Tanaman.

\begin{tabular}{ccccc}
\hline \multirow{2}{*}{ Perlakuan } & \multicolumn{4}{c}{ F. hitung dan signifikan } \\
\cline { 2 - 5 } & Sebelum OT & Setelah OT & Fase VT & Fase GT \\
\hline T & $1,53^{\text {tn }}$ & $0,09^{\text {tn }}$ & $0,05^{\text {tn }}$ & $5,80^{\text {tn }}$ \\
H & $0,17^{\text {tn }}$ & $0,43^{\text {tn }}$ & $0,80^{\text {tn }}$ & $0,22^{\text {tn }}$ \\
T x H & $1,68^{\text {tn }}$ & $0,02^{\text {tn }}$ & $1,08^{\text {tn }}$ & $1,73^{\text {n }}$ \\
\hline
\end{tabular}

Keterangan : $\mathrm{tn}=$ Tidak berpengaruh nyata pada taraf $5 \% ; *=$ Berbeda nyata pada taraf $5 \%$; OT $=$ Olah Tanah ; $\mathrm{VT}=$ Vegetatif tanaman $; \mathrm{GT}=$ Generatif tanaman .

Tabel 8. Uji Korelasi Antara Suhu Tanah, Kadar Air Tanah, pH Tanah dan C-Organik Tanah dengan Respirasi Tanah.

\begin{tabular}{lcccc}
\hline & \multicolumn{5}{c}{ Koefisien Korelasi (r) } \\
\hline \multirow{2}{*}{ Variabel } & \multicolumn{4}{c}{ Respirasi Tanah } \\
\cline { 2 - 5 } & Sebelum OT & Setelah OT & Fase VT & Fase GT \\
\hline Suhu Tanah & $0,37^{\text {tn }}$ & $0,03^{\text {th }}$ & $0,08^{\text {tn }}$ & $0,36^{\text {tn }}$ \\
Kadar Air & $0,16^{\text {tn }}$ & $0,20^{\text {tn }}$ & $0,55^{\text {tn }}$ & $0,45^{\text {tn }}$ \\
pH Tanah & $0,01^{\text {th }}$ & $0,14^{\text {tn }}$ & $0,03^{\text {tn }}$ & $0,16^{\text {tn }}$ \\
C-organik & $0,03^{\text {tn }}$ & td & td & $0,04^{\text {td }}$ \\
\hline
\end{tabular}

Keterangan : tn $=$ Tidak berpengaruh nyata pada taraf $5 \% ; *=$ Berbeda nyata pada taraf $5 \%$; OT $=$ Olah Tanah ; $\mathrm{VT}=$ Vegetatif tanaman $; \mathrm{GT}=$ Generatif tanaman .

Pada pengamatan sebelum olah tanah vegetasi diatas permukaan seperti gulma dan tanaman lainnya masih banyak, sehingga diduga mampu meningkatkan kelembaban dan kadar air tanah.

Hasil korelasi antara respirasi tanah dengan suhu tanah, kadar air tanah, C-organik dan $\mathrm{pH}$ tanah (Tabel 8) secara detail dapat dilihat pada tabel 63 sampai dengan tabel 76 (Lampiran), menunjukkan bahwa respirasi tanah tidak menunjukkan korelasi terhadap suhu tanah, kadar air tanah, C-organik dan $\mathrm{pH}$ pada semua fase pengamatan yang artinya respirasi tanah tidak dipengaruhi oleh sifat-sifat tanah tersebut.

\section{KESIMPULAN}

Berdasarkan hasil penelitian yang telah dilakukan dapat disimpulkan bahwa Perlakuan sistem olah tanah tidak berpengaruh nyata terhadap respirasi tanah pada semua fase pengamatan. Perlakuan aplikasi herbisida berpengaruh nyata terhadap respirasi tanah pada pengamatan fase generatif, tetapi tidak pada pengamatan sebelum olah tanah, setelah olah tanah dan fase vegetatif. Tidak terdapat interaksi antara dua sistem olah tanah dan aplikasi herbisida terhadap respirasi tanah pada semua fase pengamatan.

\section{DAFTAR PUSTAKA}

Burhannudin, I. S. Banuwa, dan I. Zulkarnain. 2015. Pengaruh sistem olah tanah dan herbisida terhadap kehilangan unsur hara dan bahan organik akibat erosi di laboratorium lapang terpadu fakultas pertanian universitas lampung. Jurnal Teknik Pertanian Lampung. 3(3) : $275-282$.

Fahmi, K. M. 2016. Pengaruh Dua Sistem Olah Tanah Dan Aplikasi Herbisida Terhadap Respirasi Tanah Pada Pertanaman Ubi Kayu (Manihot esculenta crantz). Skripsi. Lampung. $48 \mathrm{hlm}$.

Habiby, M.R., Damanik, S., Ginting, J. 2013. Pertumbuhan dan produksi kacang tanah (Arachis hypogaea L.) pada beberapa pengolahan tanah inseptisol dan pemberian pupuk kascing. Jurnal Online Agroteknologi. 1(4): 1183-1194.

Hanafiah, K. A. 2004. Dasar-Dasar Ilmu Tanah. Rajawali Pers. Jakarta. $360 \mathrm{hlm}$.

Lay, B.W. 1994. Analisis Mikroba di laboratorium. Rineka Cipta. Jakarta. $118 \mathrm{hlm}$.

Rajiman, P. Yudono, E. Sulistya Ningsih dan E. Hanuddin. 2008. Pengaruh Pembenah Tanah Terhadap Sifat Fisika Tanah dan Hasil 
Bawang Merah Pada Lahan Pasir pantai Bugel Kulon Progo. Agrin. 1(5) : 30- 38.

Suripin. 2010. Pelestarian Sumberdaya Tanah dan Air. Andi Yogyakarta. Yogyakarta.

Utomo, M. 1990. Budidaya pertanian tanpa olah tanah, teknologi untuk pertanian berkelanjutan. Direktorat produksi Padi dan Palawija, Departemen Pertanian. Jakarta.

Utomo, M., H. Buchari dan I. S. Banuwa. 2012. Olah Tanah Konservasi : Teknologi
Mitigasi Gas Rumah Kaca Pertanian Tanaman Pangan. Lembaga Penelitian Unuversitas Lampung. Lampung. $94 \mathrm{hlm}$.

Widdiana, G. N. 1995. Peranan Efektif Mikroorganisme Dalam Meningkatkan Kesuburan dan Produktivitas Tanah. Indonesia Kyusei Farming Societes. Jakarta. 17 Hal.

Yuliprianto, H. 2010. Biologi Tanah Dan Strategi Pengolahannya. Graha Ilmu. Yogyakarta. $11 \mathrm{hlm}$. 